Rev. Int. Contam. Ambie. 32 (2) 243-248, 2016

DOI: $10.20937 /$ RICA.2016.32.02.10

Comunicación breve / Short communication

\title{
APORTE DE LOS AFLUENTES A LA CONTAMINACIÓN FECAL DEL ESTUARIO DE BAHÍA BLANCA, ARGENTINA
}

\author{
María Eugenia STREITENBERGER y Mónica Diana BALDINI*
}

Departamento de Biología, Bioquímica y Farmacia, Universidad Nacional del Sur. San Juan 670, Bahía Blanca, Provincia Buenos Aires, Argentina, C.P. 8000

*Autor para correspondencia: mbaldini@criba.edu.ar

(Recibido mayo 2015; aceptado noviembre 2015)

Palabras clave: contaminación antrópica, calidad de aguas, indicadores bacterianos, área costera

\section{RESUMEN}

El estuario de Bahía Blanca, Argentina, recibe el aporte del arroyo Napostá Grande y del río Sauce Chico. El canal Maldonado y el arroyo Saladillo de García son afluentes menores cuyo aporte sólo es significativo durante periodos de elevadas precipitaciones. El objetivo del trabajo fue determinar el estado sanitario de los principales afluentes que recibe el estuario de Bahía Blanca, cuantificando las poblaciones de bacterias heterótrofas mesófilas aerobias (BH), Escherichia. coli (EC) y Salmonella spp., así como establecer el impacto que ejercen sobre el estuario. Se encontraron diferencias significativas entre los sitios muestreados tanto para EC $(\mathrm{p}<0.02)$ como para $\mathrm{BH}$ $(\mathrm{p}<0.01)$. La comparación de medias (LDS Fisher) mostró que las diferencias significativas detectadas por el análisis de varianza para ambos indicadores, correspondían al canal Maldonado. En los otros tres sitios, no se pudo afirmar que la contaminación difiriera significativamente $(\mathrm{p}<0.05)$. La presencia de Salmonela spp. se detectó en el $50 \%(11 / 22)$ de las muestras del Canal Maldonado y en el $45 \%$ (10/22) del arroyo Napostá, constituyéndose así en los cursos que mayor impacto tienen sobre el estuario. El arroyo Saladillo de García y el río Sauce Chico mostraron un comportamiento similar y no constituyen un problema de contaminación para el estuario. El estuario de Bahía Blanca está impactado por la actividad antrópica, que mantiene elevadas concentraciones de bacterias de origen fecal en determinadas zonas. Este problema persistirá si no se controlan los volcados cloacales clandestinos que llegan a través de cursos de agua dulce.

Key words: anthropogenic pollution, water quality, bacterial indicators, coastal area

\begin{abstract}
Bahía Blanca estuary, Argentina, receives the contribution of the Naposta Grande stream and the Sauce Chico river. Channel Maldonado and the Saladillo de García stream are minor tributaries whose contribution is meaningful only during periods of high rainfall. The objective of the study was to determine the health status of the main tributaries that the estuary of Bahía Blanca receives, quantifying populations of heterotrophic mesophilic aerobic bacteria (BH), Escherichia coli (EC) and Salmonella spp., as well as to set the impact they have on the estuary. Significant differences between the stations
\end{abstract}


for both $\mathrm{EC}(\mathrm{p}<0.02)$ and $\mathrm{BH}(\mathrm{p}<0.01)$ were found. The comparison of means (LDS Fisher) showed that the significant differences detected by ANOVA for both indicators corresponded to the Maldonado Channel. In the other three stations, we could not say pollution differed significantly $(\mathrm{p}<0.05)$. Salmonella spp. was detected in $50 \%$ $(11 / 22)$ of the samples of the Maldonado Channel and in $45 \%(10 / 22)$ of the Naposta stream. Maldonado Channel and Naposta stream are the courses with greatest impact on the estuary. García de Saladillo stream and the Sauce Chico river, showed a similar behavior and are not a problem of contamination of the estuary. The Bahía Blanca estuary is heavily impacted by human activity, which maintains high concentrations of faecal bacteria in certain areas. This problem will remain if the clandestine dumps sewage arriving through fresh water courses are not controlled.

\section{INTRODUCCIÓN}

Los estuarios funcionan como importantes sumideros y transformadores de nutrientes transportados desde el continente hacia el mar.

El estuario de Bahía Blanca está ubicado en el sudeste de la provincia de Buenos Aires, Argentina, entre los $38^{\circ} 45^{\prime}$ y $39^{\circ} 25^{\prime}$ 'de latitud sur y los $61^{\circ} 45^{\prime}$ y $62^{\circ} 25^{\prime}$ de longitud oeste (Fig. 1). Tiene una forma alargada en dirección NO-SE y una longitud de aproximadamente $80 \mathrm{~km}$, con un canal principal y varios canales secundarios que separan extensas planicies de marea e islas. El intercambio de agua está influenciado por un régimen de mareas semidiurno y la entrada de agua dulce está restringida a pequeñas corrientes, arroyos y ríos. El arroyo Napostá Grande, junto con el río Sauce Chico son los principales aportes de agua dulce que recibe el canal principal del estuario (Calvo-Marcilese y Pratolongo 2009). El río Sauce Chico descarga en el canal principal unos $3 \mathrm{~km}$ aguas

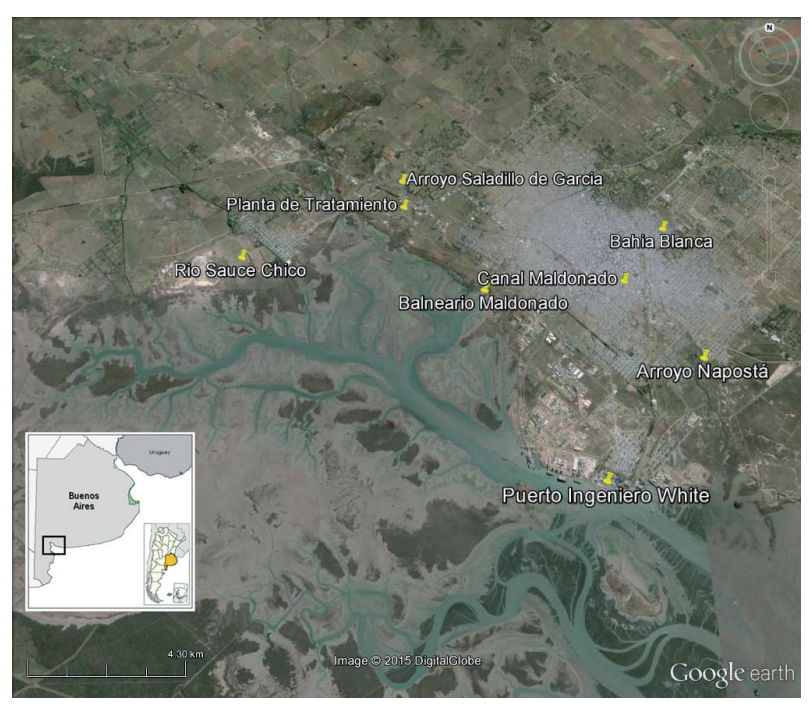

Fig. 1. Área de estudio con la ubicación de los sitios de muestreo en el estuario de Bahía Blanca, Argentina abajo de la cabeza del estuario y el arroyo Napostá Grande atraviesa la ciudad de Bahía Blanca en su curso inferior, para desembocar $1 \mathrm{~km}$ aguas abajo del puerto Ingeniero White (Pérez y Perillo 2002, Torrero y Campos 2008). El influjo en el estuario desde otros afluentes menores es intermitente y sólo significativo durante períodos de elevadas precipitaciones locales: el canal Maldonado es una vía que proviene del arroyo Napostá, el cual desemboca en el estuario junto a un balneario municipal denominado Maldonado y el arroyo Saladillo de García que confluye en cercanías de General Daniel Cerri (Fig. 1).

Las principales vías de acceso de materiales y sustancias de origen antrópico al estuario son los efluentes de los núcleos urbanos y de origen industrial (Marcovecchio et al. 2001). Sobre la costa norte de la bahía se encuentra la ciudad de Bahía Blanca y otras poblaciones menores, que suman en total más de 400000 habitantes, así como los puertos Ingeniero White, Rosales y Belgrano (Streitenberger y Baldini 2010).

Estudios previos (Streitenberger y Baldini 2010, Baldini et al 2011, Pierini et al 2012) han puesto de manifiesto que las aguas y sedimentos de ciertas zonas del estuario presentan niveles de contaminación fecal incompatibles con áreas recreativas, adjudicando la responsabilidad de este deterioro a los efluentes cloacales crudos o con tratamiento insuficiente que son volcados en sus zonas costeras.

La contaminación fecal ha sido y sigue siendo un peligro asociado con el uso de las aguas, ya que supone la incorporación de microorganismos patógenos procedentes de personas o animales, enfermos o portadores y la potencial transmisión a la población susceptible. Por ello el control sanitario de riesgos microbiológicos es importante y constituye una medida básica para mantener un grado de salud adecuado en la población humana.

Hacia finales de septiembre de 2008 se habilitó una nueva colectora cloacal con planta de tratamiento secundario que desagua en la franja interna 
del estuario en cercanías del balneario Maldonado (Fig. 1). Hasta el 2010, dicho balneario llenó sus piletas con el agua que ingresaba directamente del estuario en marea alta. En la actualidad, debido al mal funcionamiento inicial de la planta, se llena con agua subterránea ya que la proveniente del estuario no cumple con los estándares de calidad microbiológica para aguas de contacto primario (USEPA 2003, Legislación Medio Ambiente, Argentina 2006).

A pesar que en el último año la planta entró en régimen legal y los resultados de los análisis bacteriológicos a la salida del efluente cumplieron con la reglamentación vigente que es $<2000$ E. coli $/ 100 \mathrm{~mL}$ (Ministerio de Asuntos Agrarios y Producción de Argentina 2003), los valores del indicador de contaminación fecal, en la zona cercana al balneario Maldonado se mantuvieron muy altos (media: 4600 E. coli $/ 100 \mathrm{~mL}$ ). Esto sugirió la existencia de alguna otra fuente de contaminación fecal que afectaba la zona y planteó la necesidad de ponerla en evidencia.

La bacteria $E$. coli es utilizada tradicionalmente como indicador de contaminación fecal. Se asume que su comportamiento es similar al de otras bacterias de origen fecal cuando son liberadas al medio (Jeng et al. 2005). Su detección en el ambiente alerta sobre la posible presencia de microorganismos patógenos intestinales, con el consiguiente riesgo higiénicosanitario para la población que utilice las aguas con diversos fines.

En los ambientes acuáticos las bacterias heterótrofas transforman eficientemente la materia orgánica disuelta en partículas, dejando este recurso crítico disponible para el resto de la cadena trófica. Por lo antedicho, la mayor o menor densidad de bacterias heterótrofas constituye un índice de la cantidad de materia orgánica presente.

Salmonella spp. es una bacteria patógena intestinal de importancia y se encuentra con frecuencia en vertidos de granjas, en las aguas residuales humanas y en cualquier material con contaminación fecal. Los organismos del género Salmonella spp. provenientes de las heces de animales pueden permanecer en pastos y aguas, con lo que se genera la posibilidad de contaminar a otros animales. De esta manera, los insectos pueden ser un vehículo de dispersión al posarse sobre las heces contaminadas y llevarlas a múltiples lugares (Marin et al. 2009).

El objetivo del presente trabajo fue determinar el estado sanitario de los principales afluentes que recibe el estuario de Bahía Blanca, a través del estudio de poblaciones de bacterias heterótrofas mesófilas aerobias, de Escherichia coli y de Salmonella spp., así como establecer el impacto de éstas sobre el estuario.

\section{MATERIALES Y MÉTODOS}

Entre agosto de 2013 y mayo de 2015 se realizaron muestreos mensuales en las desembocaduras de los cursos naturales de agua dulce que descargan en el estuario de Bahía Blanca: Saladillo de García; río Sauce Chico y arroyo Napostá; y en el canal Maldonado, que como se mencionó anteriormente es un canal derivador construido por el hombre (Fig. 1).

En cada sitio se recolectó una muestra de agua subsuperficial (30 $\mathrm{cm}$ de profundidad) en botellas estériles de plástico de $1 \mathrm{~L}$. Las muestras se mantuvieron refrigeradas a $4 \pm 0.5^{\circ} \mathrm{C}$ hasta el momento de su análisis. El tiempo transcurrido entre la recolección y el análisis bacteriológico nunca excedió las 6 h (USEPA 2000, APHA, AWWA, WEF 2012). En todas la muestras $(n=22)$, se hicieron recuentos del indicador de contaminación fecal Escherichia coli (EC), de bacterias heterótrofas aerobias de origen terrestre $(\mathrm{BH})$ y de la bacteria Salmonella spp. Esta última se incluyó debido a que algunos de los mencionados cursos de agua atraviesan zonas donde se asientan establecimientos de producción avícola.

Para la detección de EC se utilizó la técnica de la doble capa, a fin de recuperar las bacterias estresadas por las condiciones ambientales. La revivificación se hizo durante $2 \mathrm{~h}$ en un medio de agar para recuento en placa (PCA, por sus siglas en inglés; Merck, 5463) para posteriormente adicionar el medio Endo-C-Agar (Merck, 4044; Streitenberger y Baldini 2010). La incubación se realizó a $44.5 \pm 0.5^{\circ} \mathrm{C}$ durante 24 h (Eijkman 1904). Los resultados se expresaron en Unidades Formadoras de Colonias por $100 \mathrm{~mL}$ (UFC/100mL). Para la identificación bioquímica se realizaron las pruebas IMViC y TSI agar (McFaddin 2003). Los recuentos de BH (UFC/mL) se realizaron por la técnica del agar volcado en el medio PCA. Se incubó a $30{ }^{\circ} \mathrm{C}$ durante $48 \mathrm{~h}$ (Pullés 2014). Para la búsqueda de Salmonella spp. se filtraron $250 \mathrm{~mL}$ de agua (Millipore $0.45 \mu \mathrm{m}$ de poro). Se realizó un preenriquecimiento en agua peptonada amortiguada y posteriormente un enriquecimiento selectivo, en caldo base de tetrationato. A través de una prueba rápida para Salmonella (Rapid CheK test kit; Romer Labs) se detectó la presencia de esta especie. La sensibilidad de la prueba permite detectar una Salmonella/25 mL de muestra. Los resultados positivos se confirmaron por aislamiento en agar sulfito bismuto (Merck, 5418), agar Salmonella Shigella (SS) (Merck, 7667), Hekctoen (Difco, 285340) y agar XLD (Difco, 278850). Finalmente se realizó la tipificación bioquímica para confirmar el género (Pascual Anderson y Calderón 2000, Caffer y Terragno 2008). 
A fin de evidenciar si existían diferencias en la contaminación fecal que aportan los afluentes estudiados al estuario de Bahía Blanca, se realizó un análisis de varianza simple con los datos transformados $(\log 10)$. Para determinar cuáles sitios diferían entre sí, se utilizó el método de comparaciones múltiples (LDS) de Fisher (InfoStat, Di Rienzo et al. 2011).

\section{RESULTADOS Y DISCUSIÓN}

Como se observa en la figura 2, las medias geométricas de EC del arroyo Saladillo de García y del río Sauce Chico fueron muy similares, con valores de 510 y 550 UFC/100 mL, respectivamente. La media geométrica en el arroyo Napostá fue de 5100 UFC/100 mL y en el canal Maldonado de $23000 \mathrm{UFC} / 100 \mathrm{~mL}$. Las elevadas concentraciones de $\mathrm{EC}$ en estos dos últimos cursos podrían ser un reflejo de los volcados cloacales clandestinos que reciben a lo largo de sus recorridos, ya que atraviesan la ciudad de Bahía Blanca. En el caso particular del canal Maldonado se evidenciaron grandes fluctuaciones en los recuentos, con mínimos de 1100 y máximos de $7.5 \times 10^{6} \mathrm{UFC} / 100 \mathrm{~mL}$ (Fig. 2). La misma tendencia se apreció en los recuentos de $\mathrm{BH}$, lo que indica volcados discontinuos con alto contenido de materia orgánica disuelta. En el arroyo Napostá la media geométrica de $\mathrm{BH}$ fue de $6200 \mathrm{UFC} / \mathrm{mL}$ y en el canal Maldonado de $54000 \mathrm{UFC} / \mathrm{mL}$. Las medias geométricas de BH en el arroyo Saladillo de García y el río Sauce Chico fueron similares (Fig. 3), con valores de 2900 y 4400 UFC/mL, respectivamente. En el río Sauce Chico los recuentos de $\mathrm{BH}$ fueron muy variables y los valores máximos $\left(1.1 \times 10^{5} \mathrm{UFC} / \mathrm{mL}\right)$ coincidieron con los periodos de mayores precipitaciones pluviales, donde se provocan deslaves continentales descargados hacia el estuario que contienen materia orgánica en suspensión y microorganismos del suelo. Como se mencionó anteriormente, en las aguas costeras influenciadas por el aporte de materia orgánica procedente del arrastre de los ríos, en la vegetación costera y en los efluentes domésticos y agroindustriales, las $\mathrm{BH}$ son los microorganismos intermediarios obligados entre la materia orgánica detrítica y los organismos de niveles tróficos superiores (Miravet Regalado 2003). En las Figs. 2 y 3 se aprecia que, en todos los casos, los recuentos de EC y BH siguen las mismas tendencias.

El análisis de varianza puso en evidencia diferencias significativas entre los sitios muestreados tanto para EC $(\mathrm{p}<0.02)$ como para BH $(\mathrm{p}<0.01)$. $\mathrm{Al}$ realizar la comparación de medias (LDS Fisher) entre los sitios de muestreo se vio que las diferencias significativas detectadas para ambos indicadores correspondían al canal Maldonado. En los otros tres sitios no se pudo afirmar que la contaminación difiriera significativamente $(\mathrm{p}<0.05)$.

Asimismo, se detectó la presencia de Salmonella spp. en el $50 \%(11 / 22)$ de las muestras del canal Maldonado y en el $45 \%$ (10/22) del arroyo Napostá. Debido a que ambos cursos atraviesan la ciudad de Bahía Blanca, se considera que el origen de Salmonella es humano, a través de efluentes cloacales clandestinos.

El arroyo Saladillo de García y el río Sauce Chico mostraron un comportamiento similar en cuanto a la concentración de bacterias indicadoras, lo que no constituye un problema de contaminación para el estuario. En ninguno de los muestreos se detectó

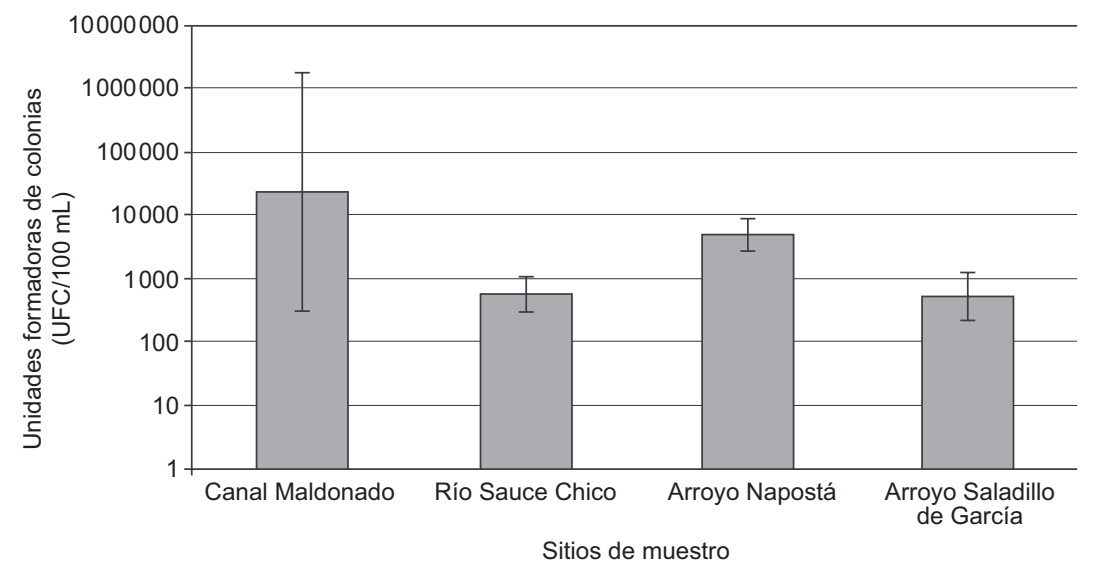

Fig. 2. Recuentos de la bacteria Escherichia coli en los afluentes que llegan al estuario de Bahía Blanca, expresados como medias geométricas \pm desviación estándar (D.S.; $\mathrm{n}=22$ ) 


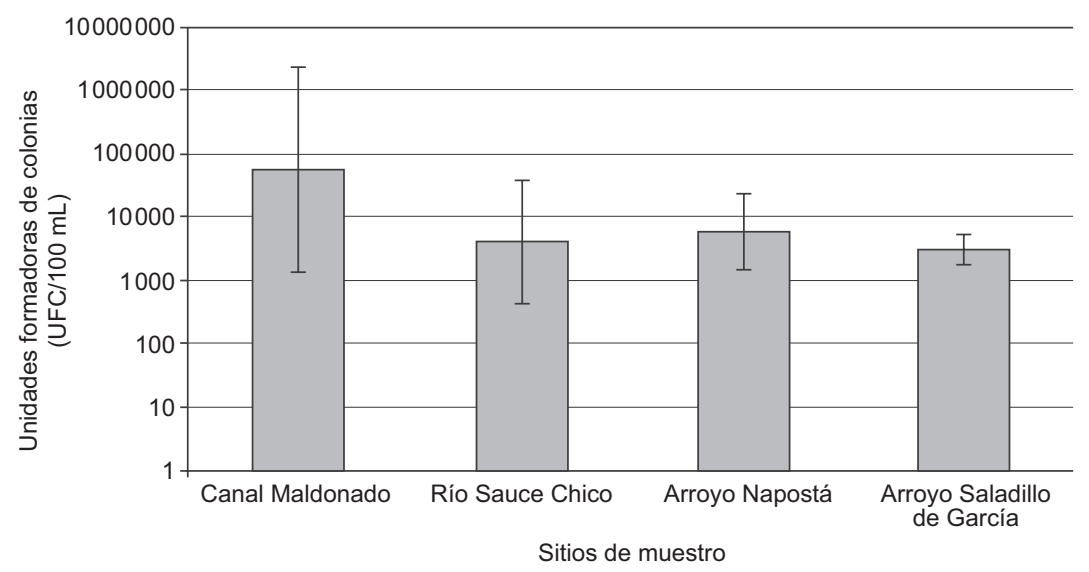

Fig. 3. Recuentos de bacterias heterótrofas mesófilas aerobias en los afluentes que llegan al estuario de Bahía Blanca, expresados como medias geométricas \pm desviación estándar (D.S.; $\mathrm{n}=22$ )

Salmonella en $250 \mathrm{~mL}$ de agua, a pesar de que ambos cursos de agua atraviesan zonas de producción ganadera y avícola. Esto podría deberse a que estas bacterias no son capaces de superar la situación de estrés a las que se encuentran sometidas al llegar al ambiente. Cabe destacar que en estos dos afluentes la mencionada zona de producción (potencial fuente de estas bacterias) dista varios $\mathrm{km}$ de los sitios de muestreo.

\section{CONCLUSIONES}

El estuario de Bahía Blanca es una zona impactada por la actividad antrópica, la cual contribuye a mantener elevadas concentraciones de bacterias de origen fecal en determinadas zonas. Se desea puntualizar la importancia de incluir en los estudios de rutina el aporte de los ríos y arroyos que desaguan en este estuario. A partir de los resultados ha quedado en evidencia que aún cuando las plantas de tratamiento de efluentes trabajen correctamente, el problema va a persistir si no se controlan los volcados cloacales ilegales que llegan a través de cursos de agua dulce.

Se requiere optimizar el tratamiento de líquidos cloacales y controlar los volcados clandestinos, principalmente al canal Maldonado que ha sido señalado por el análisis de varianza como el punto más contaminante, que además desagua en una zona del estuario con una baja renovación de agua y por lo tanto con alta fragilidad (Fig. 1).

Si bien el análisis de varianza no detectó diferencias significativas entre el arroyo Napostá, el río Sauce Chico y el arroyo Saladillo de García, las medias geométricas obtenidas en el primero ponen en evidencia una carga contaminante importante, incluyendo la presencia de Salmonella spp. Cabe destacar que el arroyo Napostá llega al estuario en una zona más externa donde el influjo oceánico es mayor, con lo que se logra una mejor dilución de los contaminantes (Fig. 1).

Para el futuro se esperan escenarios de mayor carga contaminante de efluentes a causa de un incremento demográfico y de la actividad industrial. El potencial impacto de estas actividades generará sobre el recurso una importante contaminación multicausal, que deberá ser atendida por los distintos niveles responsables de la administración del agua. Estas instancias deberán implementar los criterios de manejo y las políticas de sustentabilidad que se consideren efectivas y necesarias. A este fin el monitoreo permanente de los distintos parámetros indicadores de la evolución de la calidad del agua en el tiempo es, y seguirá siendo, una herramienta de gran utilidad a la que debe prestársele adecuada atención y financiamiento.

\section{REFERENCIAS}

APHA, AWWA, WEF (2012). Standard methods for the examination of water and wastewater. $22 \mathrm{ed}$. American Public Health Association-American Water Works Association-Water Environment Federation, Washington, EUA, $1496 \mathrm{pp}$.

Baldini M.D., Cubitto M.A. y Chiarello M.N. (2011). Estudios bacteriológicos realizados en aguas y sedimentos del estuario de Bahía Blanca. Informe 2011. [en línea]. www.bahiablanca.gov.ar/cte/doc/Informe_Bacteriologico_2011.pdf 18/04/15. 
Caffer M.I. y Terragno R. (2008). Manual de procedimiento: diagnóstico y caracterización de Salmonella spp. Ministerio de Salud. Subsecretaría de Investigación y Tecnología ANLIS “Dr. Carlos G. Malbrán”. Instituto Nacional de Enfermedades Infecciosas. Departamento Bacteriología. Servicio Enterobacterias. Buenos Aires, Argentina, 76 pp.

Calvo-Marcilese L. y Pratolongo P. (2009). Foraminíferos de marismas y llanuras de marea del estuario de Bahía Blanca, Argentina: distribución e implicaciones ambientales. Rev. Esp. Micropal. 41, 315-332.

Di Rienzo J.A., Casanoves F., Balzarini M.G., Gonzalez L., Tablada M. y Robledo C.W. (2011). Infostat software estadístico [en línea]. http://www.infostat.com.ar $18 / 04 / 15$.

Eijkman C. (1904). The fermentation test at $46^{\circ} \mathrm{C}$ as means of testing potable water. Centralblatt. Bakteriol. Abth. I. Orig. 37, 742.

Jeng H.A.C., Englande A.J., Bakeer R.M. y Bradford H.B. (2005). Impact of urban stormwater runoff on estuarine environmental quality. Estuar. Coast. Shelf S. 63, 513526. DOI: 10.1016/j.ecss.2004.11.024.

Legislación Medio Ambiente, Argentina (2006). Resolución ADA42-2006 Efluentes líquidos: Valores de calidad para el Río de la Plata y frente marítimo. Directorio de la Autoridad del Agua. Secretaria de ambiente y Desarrollo sustentable de la Nación. Boletín Oficial del 27 de enero de 2006.

McFaddin JF. (2003). Pruebas bioquímicas para la identificación de bacterias de importancia clínica. $3^{\mathrm{a}}$ edición. Médica Panamericana. Ciudad de México, México, $850 \mathrm{pp}$.

Marcovecchio J.E., Andrad L.D., Ferrer R.O., Asteasuain S.G., De Marco M.A., Gavio N.A., Scarlato R.H., Freije A.E. y Pucci A.E. (2001). Mercury distribution in estuarine environments from Argentina: the detoxification and recovery of salt-marshes after 15 years. Wetlands Ecol. Manage. 9, 317-322. DOI: 10.1023/A:1011860618461

Marin C., Hernandiz N. y Lainez M. (2009). Biolfim development capacity of Salmonella strains isolated in poultry risk factors and their resistance against disinfectants. Poult. Sci. 88, 424-431. DOI: 10.3382/ ps.2008-00241.
Ministerio de Asuntos Agrarios y Producción (2003). Resolución ADA No 336/2003. Modificación normas para efluentes líquidos. Directorio de la Autoridad del Agua. Ministerio de Asuntos Agrarios y Producción. Boletín Oficial del 15 de octubre de 2003.

Miravet Regalado M.E. (2003). Abundancia, actividad y diversidad de las bacterias heterótrofas en el Golfo de Batabanó y su uso como indicadoras ambientales. Tesis de doctorado. Ministerio de Ciencia, Tecnología y Medio Ambiente. Instituto de Oceanología, Departamento de Biología Marina. Ciudad de La Habana, Cuba, 190 pp.

Pascual Anderson M. y Calderón V. (2000). Microbiología Alimentaria. $2^{a}$ edición. Díaz de Santos S. A., Madrid, España, $441 \mathrm{pp}$.

Pérez D.E. y Perillo G.M.E. (2002). Transporte de sedimentos del Arroyo Napostá Grande, Bahía Blanca, provincia de Buenos Aires. Rev. de la Asociación Argentina de Sedimentología 9, 189-199.

Pierini J.O., Streitenberger M.E.y Baldini M.D. (2012). Evaluation of faecal contamination in Bahía Blanca estuary (Argentina) using a numerical model. Rev. Biol. Mar Oceanogr. 47, 193-202. DOI: 10.4067/ S0718-19572012000200003.

Pullés M.R. (2014). Microorganismos indicadores de la calidad del agua potable en Cuba. Revista CENIC Ciencias Biológicas 45, 32-43.

Streitenberger M.E. y Baldini M.D. (2010). Deterioro de un área recreacional por efectos del volcado de líquidos cloacales. Rev. Arg. Microbiol. 42, 307-310.

Torrero M.P. y Campos A.M. (2008). Hidrogeomorfología de la cuenca en el río Sauce Chico, Argentina. Rev. Geogr. Valparaíso, 41, 1-13.

USEPA (2000). Improved enumeration methods for the recreational water quality indicators: Enterococci and Escherichia coli. Environmental Protection Agency publication of the United States - EPA- 821-R-97-004. Office of Science and technology, Washington D.C, EUA. 53 pp.

USEPA (2003). Bacterial water quality standards for recreational waters (Freshwater and marine waters) Status Report. Environmental Protection Agency, publication of the United States - EPA- 823-R-03-008. Office of Water, Washington, D.C., EUA, 32 pp. 